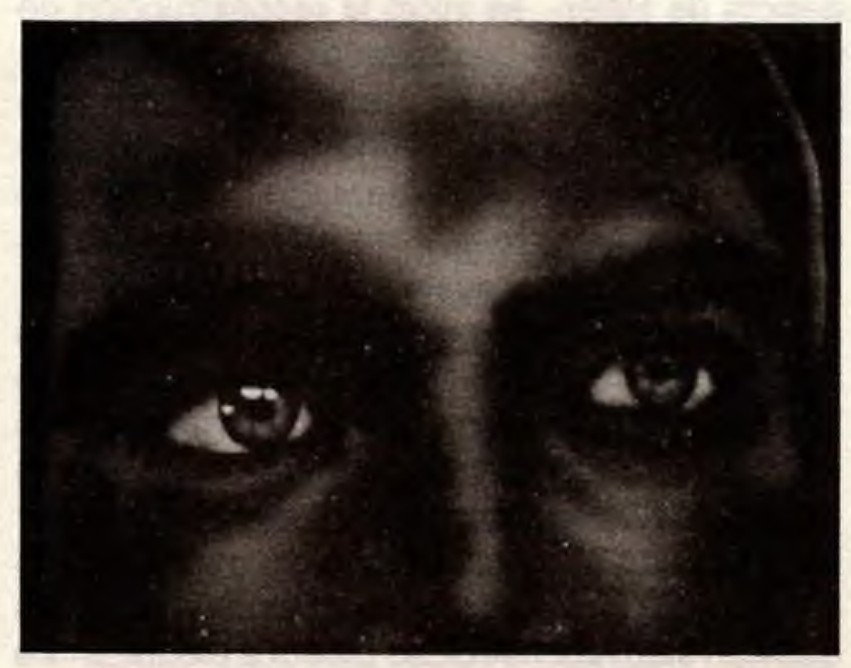

\section{Saramago: Una Propuesta de Esperanza en la Postmodernidad}

"EN BREVE, APERTURAAL PÚBLICO DE LA CAVERNA DE PLATÓN,

ATRACCIÓN EXCLUSIVA, ÚNICA EN EL MUNDO, COMPRE YA SU ENTRADA"

Abad Castañeda Borrero Magister en Literatura Docente del Programa de Lengua Castellana Facultad de Educación

Universidad Surcolombiana abad_cabo@yahoo.com

\section{Resumen}

Qué nos queda después de la primera y segunda guerra mundiales? el vacio, la nada y la desesperación, pues cómo hablar del amor, la paz, la bondad y otros principios que durante tantos años sustentaron la modernidad si esta precisamente culmina con el holocausto donde en Europa y Rusia murieron más de 70 millones de personas. Frente a este panorama desolador, la narrativa de José Saramago se presenta como una propuesta de esperanza: sólo el amor y la solidaridad nos salvan del vacio postmoderno:
Palabras Claves: Saramago, Postmodernidad, Vacio, amor y solidaridad.

\begin{abstract}
What was left for us after the First and Second World War? Throughout the bleak, empty and desolate years following the two major Worlds Wars talks about love, peace, and brotherhood among other principles were how we held on to modernity. If these talks had not taken place, modernity would have ended precisely with the Holocaust where more than 70 million persons had died throughout Europe and Russia. In the midst of this tragic time during world history, the story of José Saramago presents a ray of hope: only love and solidarity will save us from an empty postmodern society.
\end{abstract}

Key Words: Post Modemity, Emptiness, Love and Solidarity.

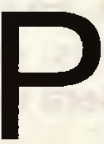

retender escribir acerca de Saramago no es tarea fácil, pues acerca de él y de su obra bastante se ha escrito ya; además lo que se diga corre el riesgo de ser refutado, $y$, hasta apaleado, pues los ojos de la crítica literaria más acérrima no dejan de mirarlo con la fascinación que causan los grandes maestros de la creación estética.

No obstante, pese a esta premisa asumiré el reto de intentar acercarme a este artífice de la palabra, teniendo como fundamento para el presente trabajo, tres de sus novelas más recientes, donde el autor plantea el problema del hombre en la sociedad postmoderna: Ensayo sobre la ceguera, Todos los nombres y La caverna.

Para empezar, es necesario precisar que cualquier intento de análisis de la sociedad postmoderna requiere un estudio juicioso, si no de todo el siglo $X X$, al menos sí de dos momentos trágicos que marcaron con huellas indelebles la vida de los hombres del pasado siglo: la primera y segunda guerra mundiales.

Este periodo, que va desde 1914 hasta 1945, principio de la primera guerra mundial y final de

'SARAMAGO, José. La caverna. Alfaguara, Madrid España, 2001. p. 454 
la segunda, marcó el fin de la época moderna e inicio de la postmoderna. Con el advenimiento de esta época, los valores de la cultura clásica occidental tales como el amor, la bondad, la solidaridad, la caridad, la paz, el concepto de hombre y el de cultura misma, desaparecen del diccionario filosófico de las humanidades. Pues, ¿cómo es posible hablar de estos valores, después de todos los atropellos y muertes de este bárbaro periodo?. Fueron masacrados en Europa y Rusia más de setenta millones de personas, algo así como si la población de Colombia fuera exterminada dos veces; además, numerosas ciudades fueron literalmente arrasadas por la barbarie.

El daño causado por las dos guerras mundiales es incalculable; el planeta físicamente colapsó: especies de flora y fauna fueron exterminadas para siempre y otras tardarían años y quizá décadas en reponerse; las capas del suelo y del subsuelo donde estallaron las bombas necesitaron lustros para volver a dar vida. En el género humano los daños son irreparables: ya nunca el hombre sería el mismo, su manera de ver el mundo sería distinta.

Antes de las dos guerras mundiales, el ser humano tenía unos conceptos y principios éticos clásicos del bien y del mal y a ellos se aferraba; para él la religión o los dogmas políticos o culturales eran su asidero, su tabla de salvación; pero una vez se desata la más infernal de las guerras todo pierde sentido y los principios y conceptos de lo clásico se revientan y sólo queda el abismo, el vacio y la nada.

Después del holocausto, ¿Cómo hablar de lo que no se puede hablar?; ¿Cómo nombrar lo innombrable?. César Vallejo expresó este sentimiento en su poema: «Un hombre pasa con un pan al hombros:

"Un hombre pasa con un pan al hombro ¿Voy a escribir después sobre mi doble? Otro se sienta, ráscase, extrae un piojo de su axila, mátalo ¿con qué valor hablar del psicoanálisis?

Alguien limpia un fusil en su cocina ¿con qué valor hablar del más allá?

Una vez finalizada la segunda guerra mundial por estos días se cumplen sesenta años de la derrota de Hitler-, se inició la reconstrucción de todas las ciudades destrozadas y las que antaño fueron ciudades grises y anticuadas, hoy son ciudades coloridas y luminosas; los espacios físicos: edificios, calles, templos, etc, fueron restaurados, pero lo que no ha sido posible es revivir el espiritu que sustentaba a esas ciudades, aún se respira en ellas el hálito de muerte que las invadió. Como dice George Steiner en su obra "En el castillo de Barba Azul" "Hermosa como es la ciudad vieja de Varsovia da la impresión de un montaje escénico; cuando camina uno por sus calles no se sienten las resonancias activas de lo vivo ${ }^{3 \prime}$. Y así mismo todas las ciudades que han sido reconstruidas piedra a piedra, muro a muro, aparecen hoy nuevas y bonitas, pero falta algo, existe en ellas un vacio, su espíritu y su aliento de vida no ha sido reconstruido y quizá ya nunca se reconstruya, pues la caída hacia el abismo es cada vez más vertiginoso.

Pero, curiosamente fue la destrucción causada por las dos guerras mundiales lo que hizo posible el desarrollo de una cultura progresista en diferentes órdenes: en lo urbanístico, se reconstruyen y remodelan las ciudades; en los modos de producción, se instalan plantas industriales completamente modernas; en lo tecnológico y científico, se inicia la carrera por reducir las distancias geográficas del planeta $e$ incluso por la conquista del espacio.

Luego de este aciago periodo, las ciencias se han desarrollado tanto, que han logrado inventos insospechados para el hombre, al punto que hoy por hoy algunos teóricos ya no hablan de postmodernidad, para ellos este término es caduco, sino de lo posthumano, un hombre que está más allá de lo humano, es decir, un ser que logra superar su mera condición de mortal y ser limitado, para convertirse en el Superhombre capaz de detener el envejecimiento, controlar los dolores y sufrimientos, decidir cómo prefiere que sean sus descendientes $e$ incluso detener la propia muerte. Este ser, dice el pensador

\footnotetext{
2 VALLEJO, César. Antologia poética. Bogotá: Oveja negra, 1982. p. 297

${ }^{3}$ STEINER, George. En el castillo de Barba Azul. p.85
} 
mexicano Miguel Barrón Mesa, en su texto El regreso del Superhombre:

"Supuestamente, este hombre del futuro será más inteligente que cualquier genio que hubiera existido con anterioridad (Einstein incluido) e inmune a las enfermedades $y$ al envejecimiento, de modo que tendrá vigor y juventud por siempre. Sus capacidades emocionales estarán tan extendidas que experimentará un placer sublime ante el amor y la belleza artística. Podrá vivir en un paraiso interior permanente mediante la recalibración y estimulación computarizada de sus centros de placer cerebrales. Jamás se sentirá cansado ni se irritará con los detalles insignificantes de la vida diaria" Más adelante el mismo autor afirma: "EI posthumano podría pedir que le implantaran en el puerto paralelo de su rapado cráneo el chip conteniendo la última edición de la Enciclopedia Británica y en el puerto serial el texto más reciente de Springer sobre la teoría de supercuerdas. De este modo sería un experto de la noche a la mañana en cualquier disciplina que se le ocurriera y no tendria que pasar años en una universidad soportando aburridos profesores, ni pasando en vela incontables noches leyendo gruesos y pesados libros."

Como vemos, este hombre no será un humano, estará más allá de la condición humana. Pero ese nivel avanzado de superación no es alcanzado por efectos de la evolución natural, sino fruto de los logros de la ciencia.

Visto a la ligera, este proyecto de Superhombre o Posthumano es llamativo, pues el hombre no sólo estaría venciendo el paso del tiempo con sus consecuentes estragos, -lo cual por fin haría realidad el mítico sueño de la eterna juventud-, sino todas las leyes naturales de la física y la química; no obstante, y esto es lo peor, la conciencia de lo ético y lo moral desaparecerían de la condición humana, pues lo que se pretende es crear una máquina humanoide capaz de todo, menos de seguir sus propios códigos morales.

\footnotetext{
${ }^{4}$ BARRÓN MESA, Miguel. El regreso del Superhombre,
} Emma@correo.dzc.vam.mx

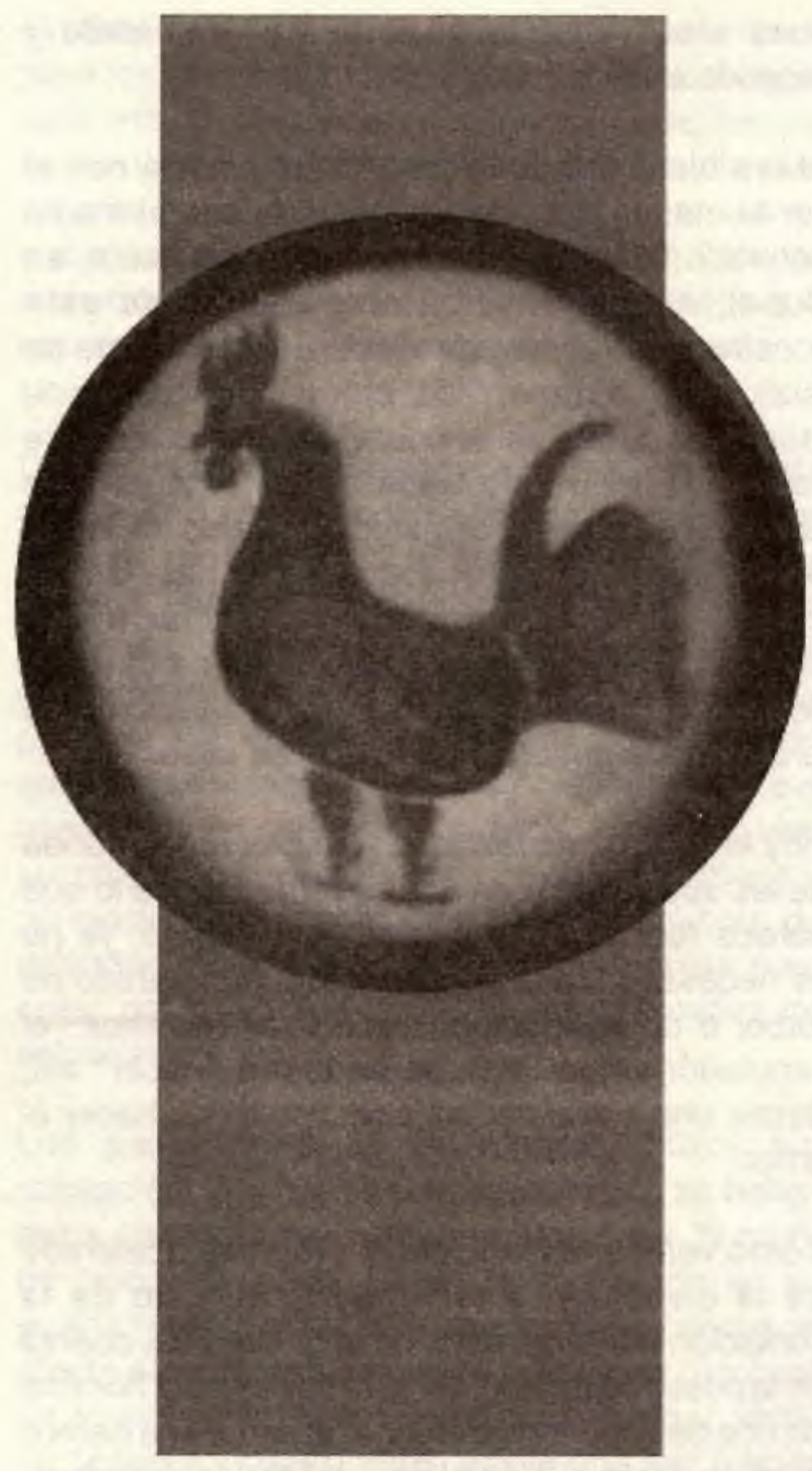

Este Superhombre difiere sustancialmente del Superhombre que hacia finales del siglo XIX planteara Nietzsche, pues éste tendría completo dominio sobre sí mismo y estaría en libertad para seguir sus propios códigos morales; en tanto que aquél estará al albedrio de lo que le programen en su cerebro. Aquí la eterna juventud, la felicidad permanente o el amor absoluto programados en un laboratorio se convierten en la alienación más deprimente para el hombre, pues la vida humana cobra importancia precisamente en el delicioso juego de la diversidad: "Hay dias en que somos tan móviles, tan móviles..."

La aparición de este tipo de Superhombre desaparecerá completamente el concepto clásico del humanismo que afirma que el hombre es único e irrepetible; este principio ya no será verdad, 
pues efectivamente si podrá ser duplicado y repetido en el laboratorio.

Ahora bien, si todo lo anterior es posible con el ser humano, ¿qué no será posible con el medio natural?. Ya existen islas donde no las habia; en Dubai, Arabia Saudita, mar adentro se está construyendo el megaproyecto de un conjunto de islas que simulan los cinco continentes -, montañas donde antes había llanuras, ríos donde habia desiertos, nevados en los lugares más calientes de la tierra, el mar lo han traido al interior de los paises, etc. Pero todo esto no pasa de ser mera apariencia, un juego de la ilusión y la fantasía, todo es representación de La caverna de Platón, donde el hombre pierde la noción de lo que es verdadero y de lo que es falso.

Hoy en la postmodernidad, vivimos en el mundo de las apariencias, en una caverna, donde lo que parece real no es real, todo es simulado; ya no es necesario ir a la cancha a jugar un partido de fútbol o de básquetbol, para eso tenemos el simulador virtual, todo lo podemos "hacer" allí, desde una competencia ciclística hasta hacer el amor.

Como vemos, es tangible el progreso acelerado de la ciencia y la tecnología; más no de la condición humana; ésta, es la que menos cuenta en la postmodernidad, en esta sociedad el hombre carece de importancia alguna, al punto que hemos perdido hasta el más elemental de los derechos: El derecho al nombre. Esto lo observamos en la cotidianidad de las ciudades y aún en la de los pueblos donde la gente ya no saluda ni se dirige al otro por el nombre propio, y asi lo conozca, se limita a pronunciar la más despersonalizada y común de las palabras: vecino. ¡Hola vecino!.

Este sentido de innominación, de personajes sin identidad y sin rostro es una constante en las tres novelas mencionadas de Sararnago; incluso en la primera que publicó: Ensayo sobre la ceguera (1995), no aparece ni un solo nombre; la despersonificación es de tal grado que a cada personaje se le nombra de acuerdo al oficio que desempeña, a la profesión que ejerce o a algún rasgo físico que lo caracteriza, por ejemplo: el primer ciego, fue quien primero perdió la vista; el niño estrábico, tiene un ojo desviado; el viejo de la venda negra, tiene una venda negra que le cubre uno de sus ojos ya perdido; la chica de las gafas oscuras, utiliza siempre gafas oscuras; el médico, efectivamente es médico; la mujer del médico, es la esposa de aquél; el ladrón, etc.

Los personajes de esta novela tienen plena conciencia de que viven en un inframundo donde todos los derechos les han sido vulnerados, donde lo que menos importa es el ser humano. Miremos lo que al respecto expresa la esposa del médico:

"... tan lejos estamos del mundo que pronto empezaremos a no saber quiénes somos, ni siquiera se nos ha ocurrido preguntarnos nuestros nombres y para qué, ningün perro conoce a otro perro por el nombre que le pusieron, identifica por el olor y por él se da a identificar, nosotros aquí somos como otra raza de perros, nos conocemos porla manera de ladrar, por la manera de hablar, lo demás, rasgos de la cara, color de los ojos, de la piel, del pelo, no cuenta, es como si nada de eso existiera6".

En la novela Todos los nombres, sucede igual; todos los nombres, irónicamente no es ningún nombre; pues si bien es cierto que el personaje central de la obra, el único en recibir nombre, se llama José, éste carece de apellido; además el nombre no está puesto al azar, Saramago asi debió pensarlo, es el nombre más anodino que puede existir en el mundo, tanto asi que por extensión todos los hombres nos llamamos José, así como todas las mujeres Maria, por lo tanto llamarse de esta manera es prácticamente carecer de nominación; en otras palabras, el nombre José, aquí no es propio, es común:

..."Cuando a don José se le pregunta cómo se llama o cuando las circunstancias le exigen que se presente, soy Fulano de Tal, nunca le sirve de nada pronunciar el nombre completo... ${ }^{71}$

Todos los nombres, es la tarea que desde el anonimato emprende don José, con el deseo de organizar la cronología de todos los nombres que giran alrededor de personas famosas que aparecen en revistas y periódicos que él

\footnotetext{
${ }^{5}$ BARBAJACOB, Portino, Canción de la vida profunda.

- SARAMAGO, José. Ensayo sobre la ceguera. Punto de lectura, Madrid España, 2001 p. 84
} 
caprichosamente colecciona; ese deseo absurdo de organización es la alegoría de alguien, quizá un ser divino, que quiere ordenar el caos del universo, lo cual finalmente no es posible, pues una vez medianamente ordenado vuelve al desorden, al caos inicial; bien, por muerte del coleccionista o por fatiga del mismo.

Todos los nombres es un sólo nombre: José, y el nombre José son todos los nombres y ninguno. Personas como José, como este José se encuentran en todas partes y ocupan su vida, o mejor, la malgastan coleccionando cachivaches y queriendo ordenar lo que no puede ser ordenado.

Son múltiples, miles los personajes de esta novela, somos los seres humanos que poblamos este planeta quienes nos encontramos en esta obra, y todos aparecemos sin rostro, sin identidad; para reconocernos basta que nos llamen la señora del sótano izquierdo, la señorita del segundo piso derecho, o como sucede cotidianamente en el ejercicio de la salud: el paciente de la cama diez; o peor, el paciente de SIDA.

En La caverna, el número de personajes también es ilimitado, el Centro como un fetiche casi religioso -existe una necesidad imperiosa, aunque inexplicable, de estar dentro de él-, los aglomera a todos; no obstante, sólo tienen nombre cuatro de ellos: Cipriano Algor, su hija Martha Algor; Marcial Gacho, esposo de Martha, e Isaura Madruga o Estudiosa. El perro de la familia Algor recibe nombre de casualidad: Encontrado, pues se habia perdido y por aquellas cosas del destino encontró a esta familia y con ella se quedó.

Dentro de este mismo orden de ideas, es importante tener en cuenta el valor significativo de los apellidos Algor y Gacho, el primero significa frio intenso del cuerpo, preanuncio de fiebre; lo cual tiene un sentido estrechamente ligado con el personaje frío y solitario que es Cipriano. El segundo, es la parte del cuello del buey en que se asienta el yugo; efectivamente Marcial como guarda del Centro está subyugado a la maquinaria invisible y alienante de ese Centro.

'SARAMAGO, José. Todos los nombres. Punto de lectura, Madrid España, 2002 p.19
Finalmente, la carencia de nombres no solo es para los personajes; las ciudades, las calles, el pais etc, también carecen de nominación; no existe un sólo lugar que tenga nombre; lo que permite leer que Saramago utiliza el mundo como escenario de su narrativa. Esa innominación es la metáfora del hombre anónimo y masificado que sobrevive en un mundo postmoderno caótico y sin nombre.

De otro lado, la triada literaria de Saramago está atravesada por un sentimiento característico del hombre postmoderno: la soledad. Nunca antes el ser humano se había sentido tan solo en el universo; nunca antes había sentido tanta orfandad en medio de tanta gente. Las calles, los parques y los centros comerciales siempre están atestados de multitudes, pero paradójicamente el hombre es un náufrago, está solo; cada uno vive su propia tragedia, no hay intereses comunes, no existe nada que lo una. Este sentimiento de orfandad quizá sea la razón más poderosa para optar por el suicidio como única alternativa de solución.

Los personajes de Saramago, todos sin excepción, padecen esta enfermedad, se hallan solos en medio de multitudes. Don José, hombre de cincuenta años, soltero, vive aislado en su apartamento junto a la Conservaduría, carece de afecto alguno, nadie lo visita ni le dirige palabras de amistad, y en él como en Cipriano Algor, viudo de sesenta y cuatro años, existe una sed infinita de compañía, de afecto; al punto que cualquier expresión de cariño, por insignificante que sea, es suficiente para llenar el alma vacia del ser. Brevemente observemos lo que le sucedió a don José con una mujer a quien éste visita:

"No la molesto más, le agradezco su paciencia y su gentileza, y le pido que me disculpe... Al contrario de lo que acaba de decir, yo no estaba tranquila, estaba sola, contarle algunas de las cosas tristes de mi vida ha sido como quitarme un peso de encima. Le besé la mano como la primera vez, pero entonces ocurrió algo que no esperaba, ella mantuvo mi mano agarrada y se la llevó a los labios. Jamás en mi vida una mujer me habia hecho esto, lo senti como un choque en el alma, un estremecimiento 
del corazón y aún ahora, de madrugada, tantas horas pasadas mientras escribo en el cuaderno los acontecimientos de este día, miro mi mano derecha y la encuentro diferente, aunque no sea capaz de decir en qué consiste la diferencia, debe ser cosa de dentro, no de fuera ${ }^{8 \prime}$.

En Ensayo sobre la ceguera, la orfandad que padecen los personajes es más lamentable aún, pues ni el estado de miseria física y espiritual en el que se hallan en el manicomio, es motivo para unir esfuerzos y luchar contra la ceguera que los azota y contra el régimen que los tortura. Cada personaje, excepción la esposa del médico, lucha por la sobrevivencia personal, cada uno se aferra a la idea de ¡Sálvese quien pueda!. Aqui, el sentido de orfandad es inconmensurable, el hombre desciende al estado más bajo, hasta perder prácticamente su condición humana y regresa a sus origenes más primitivos y salvajes donde la lucha es feroz por la supervivencia. Estos hombres caídos en desgracia por la ceguera blanca son similares a las hordas primitivas $y$ salvajes; sólo que éstas vivian en un planeta puro $e$ intacto $y$ aquellos en un mundo destruido y contaminado: "Volvemos a la horda primitiva, dijo el viejo de la venda negra, con la diferencia de que no somos unos cuantos millones de hombres y mujeres en una naturaleza inmensa e intacta, $y$ si millares de millones en un mundo descarnado y consumido, y ciego, añadió la mujer del médico"

La ceguera física que padecen los personajes es la metáfora de nuestra ceguera espiritual, en realidad somos ciegos no de la vista sino del alma. La indiferencia, la apatía, la indolencia es lo que nos hace ciegos y solitarios.

Y asi como la ceguera blanca es la metáfora de nuestra ceguera espiritual, el manicomio es la metáfora del infierno donde todo es dolor, llanto, sufrimiento $y$ angustia infinitos.

La visión general del manicomio, donde inicialmente son hacinados los enfermos de la ceguera blanca, luego la ciudad y el pais, sin nombres, son dantescos; y así como Dante se anticipó varios siglos a describirnos ese infierno que durante la primera y segunda guerra mundiales serían los campos de concentración
Nazi, -además la asociación es perfecta, en La Divina Comedia, el fuego es eterno, en los campos de concentración están los hornos crematorios, en la obra de Dante como en los campos de la muerte los olores son azufrados y pestilentes; los dos finalmente conducen a la muerte en medio de los más terribles dolores- , Saramago unas cuantas décadas después nos recordará que ese infierno dantesco, que esos campos de concentración aún viven en la postmodernidad.

Efectivamente, este manicomio es un infierno, un campo de concentración Nazi: alli reina la oscuridad, el sufrimiento físico y moral son terribles, los olores son nauseabundos, apestan, todo huele a mierda, a descomposición, las cañerías están taponadas, hay varios cadáveres insepultos, no hay agua, cada uno hace sus necesidades en cualquier lado.

La arquitectura física del edificio donde están encarcelados los ciegos también es una réplica del infierno y de los campos de concentración; existe una sola entrada y quien entra no vuelve a salir, todos los lugares están flanqueados para evitar que alguien se pueda evadir; las paredes son altas y lisas para que nadie las escale, las ventanas son muy pequeñas y están casi a la altura del techo, lo que no deja esperanza alguna de comunicación con el mundo exterior. Además, asi como en el infierno dantesco existen demonios que fustigan incesantemente a las almas condenadas, en los campos de concentración Nazi eran los esbirros de Hitler quienes tenían la tarea de torturar y condenar a los judios; y en el manicomio son los soldados del Estado, - ¿Cuál Estado? Cualquier Estado-, los encargados de vigilar celosamente que ninguno de estos condenados escape.

Cuán equivocados estaban Voltaire y sus ilustrados contemporáneos hacia mediados del siglo XVIII cuando creian que con la sociedad civilizada se habían acabado las torturas y otras bestialidades cometidas contra el género humano:

"A mediados de la década de 1760, después del caso Calas, Voltaire y sus ilustrados

\footnotetext{
${ }^{8}$ bid, p.252

` SARAMAGO, José. Ensayo sobre la ceguera. P.342
} 
contemporáneos expresaban la confiada creencia de que las torturas y otras bestialidades practicadas en súbditos o enemigos habian terminado para siempre en la sociedad civilizada ${ }^{10 "}$

No. No han terminado. Las torturas y los crimenes de lesa humanidad continúan y conviven en nuestra cotidianidad postmoderna, y lo peor, siempre amparados en el falso principio clásico de la democracia.

$Y$ esto es lo que recrea Saramago en Ensayo sobre la ceguera, una realidad que no es la del papel, sino la de la vida diaria de los pueblos. Bástenos citar el caso de todos los crímenes cometidos recientemente en los campos de concentración de Abu Ghraib en Irak; sólo que esta vez los verdugos no son alemanes sino gringos; pero en últimas es igual: Caín sigue matando a Abel.

Una característica más, que identifica al hombre de la postmodernidad, desarrollada magistralmente por Saramago, tiene que ver con el mundo de lo ficticio y del engaño; lo que vemos no es lo real, es la simulación de lo real; como en el Mito de la Caverna de Platón, las sombras que vemos o los ecos que escuchamos no son ni las personas ni las voces, son simulaciones, son apariencias de esa realidad; los sentidos se afectan y no tenemos claridad de lo que es verdadero y de lo que es falso.

No es gratuito que la última novela publicada de la trilogía que nos ocupa, se llame La Caverna, un mito tan antiguo, cerca de 2.500 años cumple ya, hoy cobra vigencia y Saramago nos lo recrea maravillosamente.

El mito platónico de la caverna es el mundo, y particularmente el centro comercial, lugar alrededor del cual giran todos los intereses de la vida postmoderna. Este Centro se ha convertido en eje vital del hombre de hoy; la plaza de mercado tradicional atiborrada de productos de toda índole, donde las relaciones de las personas, aunque ruidosas, humanizadas, ha sido reemplazada por un centro comercial rigurosamente organizado, donde esas relaciones no superan el intercambio frío de una transacción comercial.
El mundo de este Centro es oscuro, nadie conoce la generalidad del engranaje y su funcionamiento; alli los rostros están difuminados y no existe presencia real de lo humano; pareciera ser, como lo afirma George Steiner, que los oscurantismos de los dogmas religiosos hayan sido reemplazados por otro oscurantismo más tirano y cruel. Este Centro es más grande que la ciudad, la parte es mayor que el todo, lo que hace que para un hombre sea imposible conocerlo; ochenta años de vida ociosa no serian suficientes para conocer este enigmático mundo artificial, donde el hombre simple y sencillo se torna confuso y complicado.

En La caverna, el Centro es quizá, el personaje principal, todos los caminos conducen a él, es lugar imprescindible para la sociedad, él posee un imán invisible que atrae a los seres humanos como el dulce a las abejas. El Centro, aunque perfectamente iluminado, -estando dentro se pierde la noción real del tiempo, no se sabe si es de día o de noche,- es oscuro, nadie conoce su dinámica de funcionamiento. Además es despersonalizado y despersonalizante, no existe nada propio, todo es común, no hay rostros, sólo figuras indefinidas, se habla del jefe, del subjefe, del guarda externo o del guarda residente, nunca de personas.

En el Centro, el bombardeo de antivalores es permanente, durante las veinticuatro horas aparecen letreros con luces de neón invitando al consumo, al egoísmo, al engaño y sobre todo a la pérdida de la identidad: "Sea osado, sueñe"; "Usted es nuestro mejor cliente pero no se lo diga a su vecino"; "Vive la osadía de soñar"; "Gane operacionalidad", "Sin salir de casa los mares del sur a su alcance"; "Esta no es su última oportunidad pero es la mejor"; "Pensamos todo el tiempo en usted, es hora de que piense en nosotros"; "Traiga amigos que compren"; "Con nosotros usted nunca querrá ser otra cosa".

El Centro, como un cáncer postmoderno, está en permanente crecimiento, hacia arriba, hacia los lados, hacia abajo; nunca se detiene. Él es la visión global del mundo y del universo, allí se

${ }^{10}$ STEINER, George. Gedisa, Barcelana, 1991 p.68 
encuentra todo: el mar, las nieves perpetuas, el desierto, las montañas más encumbradas, la lluvia, el sol, etc; pero todo es falso, todo es un fraude a los sentidos; ese sol es artificial; la arena fina, blanca y atractiva es de plástico; el mar con sus olas, son simulaciones logradas por movimientos mecánicos; el aire que se respira es enlatado. Aquí encontramos el mundo condensado artificialmente. ¿Quieres visitar la Torre Eiffel? Allí está; ¿Las Pirámides de Egipto? También. ¿El Sahara?, ¿Los Alpes?, ¿La Muralla China?. Todo, todo esta alli; y próximamente se abrirá como atracción exclusiva La caverna de Platón; es decir, una caverna dentro de otra caverna, pero todo es engaño como en Las Vegas - el centro artificial más grande de juegos y de perdición del mundo- donde lo único que es auténtico, tiene que serlo, es el dinero, pues éste es la razón de ser y de vivir del Centro. Definitivamente, en el Centro encontramos todo, menos al hombre, él no cuenta , no existe, no es.

En la sociedad postmoderna, las humanidades, (la filosofía, la literatura, la música, la antropologia, etc) han sido relegadas a un segundo plano y han cobrado suma importancia las carreras que tengan que ver con la producción material y especialmente aquellas que sean muy rentables, pues el dinero; don Dinero como escribió Francisco de Quevedo, es quien material y espiritualmente sostiene a esta sociedad. Este estilo de vida le ha permitido al hombre postmoderno enriquecerse hacia fuera, pero empobrecerse hacia adentro, hay dos puertas, una hacia afuera, hacia lo material, siempre está abierta; y otra hacia adentro, la que conduce al encuentro con uno mismo, esa está cerrada.

A Cipriano Algor y a su hija Marta, la postmodernidad les cerró las dos puertas; la de afuera: el centro ya no les compra más las artesanias en barro que ellos fabrican; estas baratijas, dice el Centro, son pesadas, anticuadas y sobre todo se quiebran fácilmente como las almas humanas; en cambio todo lo que se fabrica en plástico es duro, liviano y no se rompe. La de dentro: si ya nadie compra las artesanias en barro, si ya nadie las quiere ni regaladas, ¿Para qué se construyen? $Y$ si no se construyen no hay lugar al encuentro consigo mismo. El mundo plástico del Centro sepultó al artesano del barro; pareciera ser que el Creador, el dador de vida del barro haya sido reemplazado por un Creador de vida del plástico.

Visto desde esta perspectiva, el panorama que Saramago nos presenta en las tres obras citadas, es desolador; pero mientras haya vida, dice el autor, hay esperanzas: "Como nuestros abuelos más o menos creian, habiendo vida hay esperanzas $^{11 "}$.

Efectivamente Saramago nos deja abierta una ventana hacia la esperanza: el amor y la solidaridad. Frente a la soledad, la innominación, el vacio, el absurdo y la alienación de la sociedad postmoderna, la propuesta es el amor y la solidaridad como alternativa de salvación. Sólo si somos capaces de amar y de ser solidarios lograremos recuperar nuestra desbaratada condición humana.

No en vano don José se enamora platónicamente de la mujer de quien busca su pasado; pues gracias a ese amor ideal experimenta un cambio esencial en su vida que lo lleva a rebelarse contra la Conservaduría que lo explota y lo desconoce como persona. Este personaje evoluciona del anonimato al reconocimiento; inicialmente es tímido, miedoso e inseguro, luego es autónomo, decidido y valiente.

La búsqueda absurda de la mujer desconocida se convierte en la razón de ser, en el sentido de la existencia de don José; sólo a través de esa búsqueda él encuentra una razón para vivir.

En Ensayo sobre la ceguera, sólo el amor y solidaridad inmensos de la mujer del médico logran rescatar al género humano del infierno de la indiferencia y la soledad. Todo el mundo queda ciego; menos ella, quien dedica todas sus fuerzas y su amor para guiarlos a través del inframundo, como Virgilio a Dante en La Divina Comedia, hasta lograr sacarlos a un mundo nuevo donde todos recuperan la vista; todos vuelven a ver; y volver a ver es volver a nacer; pero es un renacer a la conciencia y al humanismo.

En esta novela fue necesario que el hombre tocara

11 SARAMAGO, José. La caverna. p.371 
fondo, que descendiera a lo más hórrido de la existencia para tomar conciencia de que sólo el amor y la solidaridad nos salvan del vacio y la nada. Con esta obra Saramago nos devuelve la vista, nos permite ver el mundo a través de la esperanza, pues quien la ha perdido se ha vuelto ciego que es como estar muerto: "... está visto que aquí nadie puede salvarse, la ceguera también es esto, vivir en un mundo donde se ha acabado la esperanza" ${ }^{12 "}$.

Finalmente leer Ensayo sobre la ceguera, es leer la historia de un viaje, como el de Dante en La Divina Comedia, que inicia con una larga temporada en el infierno, y termina en el cielo donde todo es luz y conciencia.

En La caverna sucede igual, Cipriano Algor e Isaura Madruga; Martha Algor y Marcial Gacho, comprenden que sólo el amor y la solidaridad los salvan del monstruo de mil cabezas que cada vez se multiplica más, y terminan huyendo luego del hallazgo de los seis cadáveres enterrados en los sótanos más profundos del Centro como alegoría del mundo muerto y sepultado por el Centro mismo.

"Al final uno debe comenzar a amar para no enfermarse ${ }^{13 "}$

\footnotetext{
12 SARAMAGO, José . Ensayo sobre la ceguera. P.282
}

${ }^{13}$ STEINER, Op. Cit. p.74 